\title{
Relevansi Search Engine Optimization (SEO) On-pages Di 2021
}

\author{
${ }^{1}$ Toto Indriyatmoko, ${ }^{2}$ Majid Rahardi \\ ${ }^{1}$ Prodi D3 Teknik Informatika Universitas Amikom Yogyakarta \\ ${ }^{2}$ Prodi S1 Informatika Universitas Amikom Yogyakarta
}

\author{
Alamat Surat \\ Email: toto.indriyatmoko@amikom.ac.id*, majid@amikom.ac.id \\ Article History: \\ Diajukan: 30-03-2021; Direvisi: 14-04-2021; Diterima: 28-04-2021
}

\begin{abstract}
ABSTRAK
Search Engine Optimizion (SEO) merupakan metode yang dilakukan untuk meningkatkan kualitas dari sebuah website dari sudut pandang peringkat di mesin pencari termasuk mesin pencari google. Google bukan menjadi sebuah rahasia lagi adalah sebuah perantara bagi website untuk mendatangkan pengunjung. Semakin bertambahnya pengguna internet berbanding lurus degan semakin bertambahnya jumlah website yang ada di dunia. Hal itu membuat semakin tingginya pula kompetisi website untuk meningkatkan peringkat di mesin pencari. Banyak cara yang bisa dilakukan utuk meningkatkan peringkat, salah satu caranya adalah dengan menggunakan teknik SEO on-pages. Pada teknik ini banyak sekali tips dan trik yang dapat dilakukan, namun seiring pembaruan yang terus dilakukan oleh google, apakah teknik ini masih berfungsi atau tidak, itu yang menjadi sebuah pertanyaan. Dalam tulisan ini membahas tentang apakah teknik SEO on-pages masih relevan terhadap pembaruan yang dilakukan oleh google dan mencari fakta-fakta yang ada di literatur terkait dan membandingkan dengan apa yang terjad sekarang di laman google.
\end{abstract}

Kata kunci: Search Engine Optimizion; SEO on-pages; website; Google.

ABSTRACT

Search Engine Optimization (SEO) is a method used to improve the quality of a website from the point of ranking in search engines including the Google search engine. Google is an intermediary for websites to bring visitors. The increasing number of internet users is directly proportional to the increasing number of websites in the world. This also makes the website more competitive to increase rankings in search engines. There are many ways you can do to increase rankings, one of the ways is to use on-page SEO techniques. In this technique there are lots of tips and tricks that can be done, but as updates continue to be made by Google, whether this technique still works or not is a question. In this paper, it discusses whether on-page SEO techniques are still relevant to updates made by Google and looks for facts in related literature and compares with what is happening now on Google pages.

Keywords: Search Engine Optimizion; SEO on-page; website; Google

\section{PENDAHULUAN}

Website dari fungsinya menjanjikan kemudahan bagi setiap penggunanya untuk membantu kehidupan sehari-hari, mulai dari berkomunikasi, mencari informasi, menyebarkan informasi, bahkan untuk menjual produk (Wu, Dong, Shi, Liu, \& Ding, 2020). Contohnya ada toko online seperti bukalapak, shopee, tokopedia dan lain sebagainya yang memberikan fasilitas bagi konsumen untuk membeli dan menjual barang. Tapi ad juga website yang menjual produk mereka sendiri, seperti lazada, bhineka, matahari mall, dan lain sebagianya. Mereka menjual produk mereka sendiri. 
Tentu dibelakang mereka sudah banyak investor yang berani mengeluarkan banyak uang untuk memasarkan brand mereka sehingga masyarakat sudah tidak asing lagi dengan nama mereka. Lantas, bagaimana dengan brand yang baru memulai dengan sedikit modal ? Apakah mereka juga nantinya bisa meningkatkan brand awareness mereka?

Untuk meningkatkan brand awareness yang murah salah satunya adalah dengan membangun website. Tentu saja bukan hanya menbangun website lalu ditinggalkan begitu saja, harus ada proses perawatan dan lain sebagainya. Tentu saja sebuah website harus mudah diakses untuk mendapatkan pengunjung, salah satunya adalah dengan berada di peringkat atas mesin pencari, google misalnya.

Sudah menjadi rahasia umum jika google adalah mesin pencari yang paling banyak digunakan oleh pengguna internet diseluruh dunia. Jadi, secara logika google merupakan salah satu sumber trafik pengunjung paling besar yang bisa kita dapat. Apalagi jika website kita berada pada halaman pertama di mesin pencari google, tentu itu merupakan sebuah prestasi tersendiri bagi website kita. Lantas bagaimana cara masuk ke halaman 1 mesin pencarian google? Salah satu jawabanya adalah dengan menerapkan Search Engine Optimization (SEO) (Wang, Li, \& Zhang, 2011).

SEO memungkinkan website untuk bisa masuk ke halaman mesin pencarian. Ada banyak metode $S E O$ yang bisa dilakukan, salah satunya SEO on-pages. Dalam tulisan ini penulis akan mengupas masalah $S E O$ on-pages dari relevansi terhadap aturan dari google serta apa saja yang berpengaruh di bagian $S E O$ on-pages.

\section{METODE}

Penelitian ini menggunakan metode kajian literatur yang terdapat pada buku, jurnal maupun website yang relevan dengan penelitian yang oleh pakar yang ahli dibidangnya untuk mendapatkan data dan pembanding (Habsy, 2017). Data-data dari literatur dibaca dan dicatat kemudian dipilih sesuai topik bahasan kemudian dibahas ulang dalam satu penelitian.

\section{HASIL DAN PEMBAHASAN}

\subsection{Search Engine Optimization (SEO)}

Perkembangan teknologi membuat usaha juga terdampak. Dari yang dahulu melakukan teransaksi secara langsung, menjadi teransaksi virtual. Pemanfaatan teknologi membuat marketing dengan selebaran, poster dan baliho menjadi pemasaran yang terlihat kuno. Dengan memanfaatkan pemasaran digital, kita hanya perlu memasang iklan disatu tempat namun dapat dilihat oleh banyak calon pembeli disemua belahan bumi.Salah satu penerapan pemasaran digital yang bisa digunakan adalah memanfaatkan website. Website yang dioptimmalisasikan dengan $S E O$ memiliki peluang yang sanga tinggi untuk digunakan sebagai media promosi digital. SEO adalah salah satu metode yang mampu untuk meningkatkan peringkat website di mesin pencari google (Harto, 2019).

Tujuan dari SEO adalah uantuk memberikan pengalaman terhadap para pengguna mesin pencari untuk mendapatkan hasil yang sesuai dengan apa yang diinginkan oleh pengguna. Ketika mesin pencarian menerima kata kunci dari apa yang ditulis di kotak mesin pencarian, algoritma dari mesin pencari bekerja untuk mencari tulisa yang relevan dengan kata kunci yang dituliskan. Setelah mendapatkanya, lalu mesin pencari menampilkan hasil dari pencarrian di layar monitor, hasil dari pencarian tersebut biasa disebut Search Engine Results Page (SERP) (Barbar \& Ismail, 2019).

$S E O$ digunakan untuk meningkatkan peringkat website di mesin pencari dan memudahkan calon pembaca untuk menemukan website yang mereka inginkan. Website yang telah diunggah ke internet akan secara otomatis dibaca oleh algoritma google ( $\mathrm{crawl}$ ) dan nantinya informasi yang ada di website tersebut yang relevan dengan kata kunci yang sering dicari maupun yang belum pernah dicari dn dianggap google sebagai informasi yang bagus akan disimpan dalam database google (indexing) yang nantinya akan dikeluarkan ketika ada seseoang yang mencari dengan kata kunci yang relevan terhadap website tersebut (Prakash, 2020). 
Dewasa ini SEO juga sangat dikaitkan dengan personal branding. Hal itu dilakukan untuk meningktkan brand awarenss para calon konsumen. Ketika calon konsumen mendengar nama sebuah produk, biasanya mereka akan mencari informasi produk tersebut melalui internet. Ada calon konsumen yang langsung mencari dengan nama produknya, dan ada pula yang mencari dari produk apa yang mereka cari. Untuk konsumen yang mencari produk tersebut dengan nama merek produk dagang, tentu hasil pencarian langsung menuju website yang menyediakan informasi produk dari merek tersebut. Namun, bagi calon pelanggan yang mencari produk berdasarkan jenisnya, tentu banyak variasi merek yang akan muncul dihasil pencarian (SERP), Disitulah fungsi SEO dibutuhkan, para pemegang merek dagang berombalomba memperbaiki SEO dari website mereka untuk menempati posisi terbaik di mesin pencari (Setiawan \& Noviyanto, 2018).

Semakin banyak website yang online di dunia maya tentunya juga menambah banyaknya indeks yang disimpan oleh database google. Informasi tersebut bagaikan pisau yang mempunyai dua sisi. Sisi tajamnya adalah tersedianya berbagai macam informasi yang bisa didapat oleh para pengguna mesin pencari sehingga pengguna bisa membandingkan dari banyak informasi yang didapatkan. Sedangkan sisi tumpulnya adalah makin sulitnya persaingan antar website untuk mendapatan posisi yang bagus di mesin pencari. Website mana yang lebih relevan dan datang dengan $S E O$ yang lebih baik akan memiliki peluang yang lebih besar untuk menempati posisi teratas dari mesin pencari (Arifin, Dengen, Setyadi, Prafanto, \& Putra, 2019).

\subsection{SEO On-pages}

Dalam jurnal yang ditulis oleh Kumar pada tahun 2019 menuliskan bahwa sebuah website memang tidak harus mempraktekan secara sengaja $S E O$ on-pages untuk menempati peringkat atas dalam hasil pencarian google (Kumar \& Paul, 2020). Namun pada kenyataanya SEO onpages dipakai untuk membuat website semenarik mungkin untuk menjaga agar pengunjung lebih lama lagi berada di website tersebut dan dilakukan tanpa sadar oleh pengelola. Salah satu contohnya adalah judul yang menarik. Pemilihan judul merupakan hal paling standar yang dilakukan seseorang untuk membuat sebuah artikel, namun dalam SEO on-pages pemilihan judul juga merupakan bagian kecil dari teknik yang dianjurkan.

SEO on-pages merupakan segala cara yang dilakukan di dalam website untuk meningkatkan peringkat ataupun terbaca di mesin pencari (Gupta, Agrawal, \& Gupta, 2016). Banyak hal yang bisa dilakukan antara lain pemilihan judul, persebaran kata kunci, anchor text, internal link, tema website, warna background, pemilihan gambar, bahkan pemilihan pola bahasa seperti pemilihan kata sambung, juga merpakan bagian dari SEO on-pages.

\subsection{Relevansi Dengan SEO 2021}

Website tentunya menjadi hal yang sangat penting bagi sebuah komunitas atau badan usaha untuk memberikan pengetahuan bagi para pembacanya (Hasugian, 2018). Bagi sebuah komunitas, website bisa digunakan untuk memperkenalkan komunitasnya, menyimpan foto atau video dari kegiatanya, membuat pengumuman, Begitupun dengan perusahaan yang ingin meningkatkan pengetahuan bagi calon konsumennya, mereka membutuhkan website untuk memperkenalkan perusahaanya. Sedangkan untuk website yang digunakan untuk berjualan, tentu tujuanya adalah untuk membuat barang yang dijual laku. Dari hal tersebut bisa diartikan bahwa webste digunakan sebagai media promosi dengan tujuan yang bermacam-macam. Jika kita mau melakukan promosi, pastinya hal yang harus ada adalah calon pelanggan atau audien. Dengan menggunakan website, pemilik berkesempatan untuk mendapatkan perhatian dari seluruh dunia. Namun, semakin banyaknya website di dunia maya secara otomatis juga akan memberikan tantangan baru berupa persaingan yang semakin ketat untuk mendapatkan perhatian dari audien. Banyak cara yang dapat dilakukan agar website kita dapat terlihat di mesin pencarian google. Salah satu caraya adalah dengan memanfaatkan Search Engine Optimization (SEO) On-pages (Eka Purwiantono, 2019). 
SEO On-pages dapat diartikan segala bentuk cara yang dilakukan di dalam websie untuk meningkatkan posisi website kita di posisi pertama mesin pencarian google (Nova et al., n.d.). Banyak cara yang dapat dilakukan, namun google memmberikan beberapa cara yang secara teratur diperbarui aturan tersebut. Seperti yang banyak orang tahu, perkembangan teknologi membuat kita harus belajar terus menerus tanpa henti untuk memahami teknologi yang tiap detik bisa berubah. Begitupula algoritma yang dibuat oleh google untuk memaksimalkan mesin pencarianya.

Sejak awal dibuat SEO On-pages menjadi hal yang sangat penting bagi website. Namun, dengan banyaknya pembaruan di mesin pencarian google, apakah SEO On-pages masih relevan jika digunakan untuk mengoptimalisasi website? dan jika masih relevan, apa saja buktinya? Berikut adalah bukti tentang strategi SEO On-pages

Setiap Google menperbarui mesin pencarinya, google juga akan memperbarui di bagian panduan mesin pencari google. Dalam sebuah artikel yang terletak di laman resmi google, google menulisakan sebuah pernyataan seperti berikut.
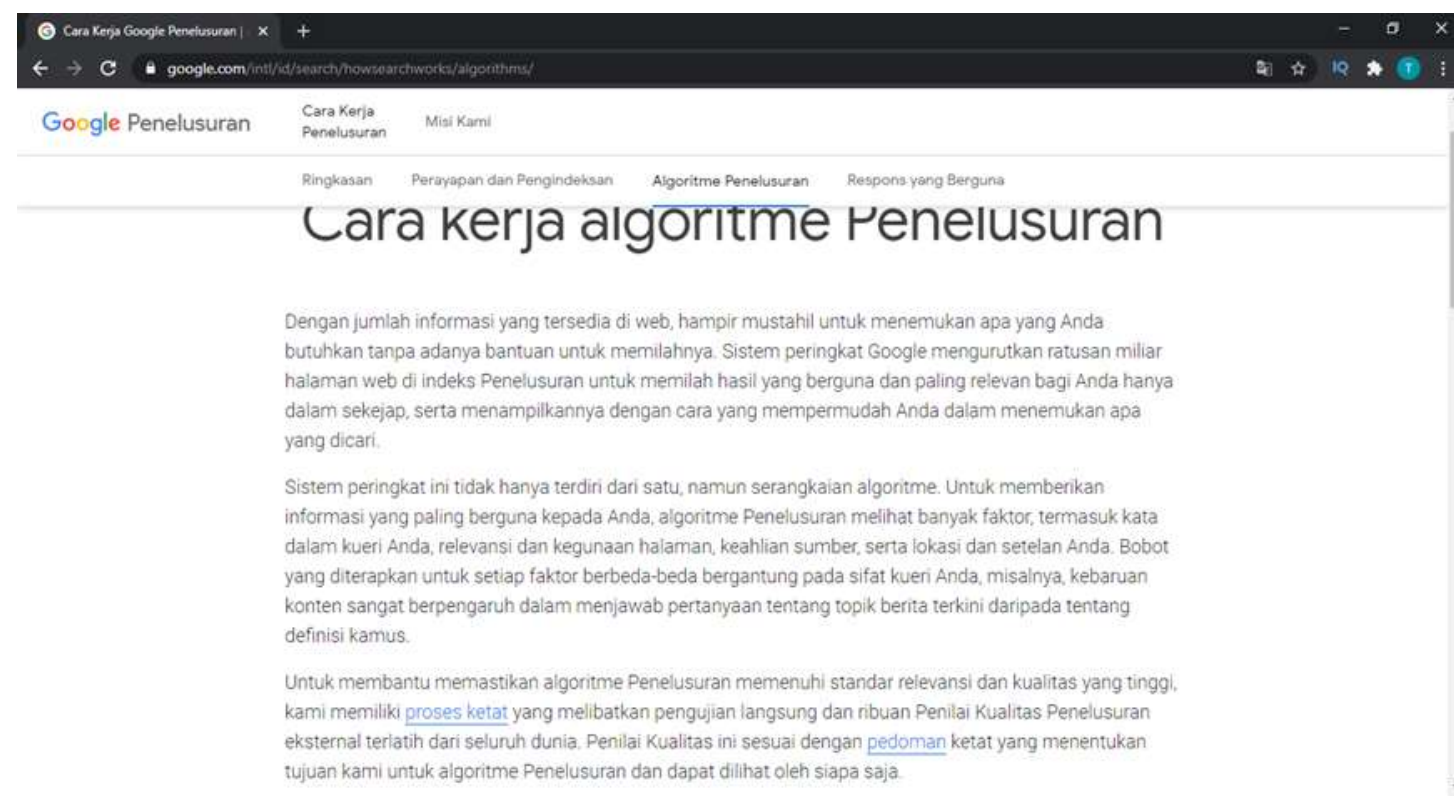

\section{Gambar 1. Cara kerja algoritma penelsuran}

Dalam Artikel tersebut, pihak google menjelaskan bahwa salah satu metode mereka untuk mencari website untuk ditempatkan di hasil pencarian teratas adalah dengan melihat apakah isi dari website tersebut sesuai dengan apa yang dicari di mesin pencarian. Selain itu google juga melakukan pengecekan apakah isi dari website tersebut asli buatan website tersebut atau hasil duplikasi dari website lain. Apakah isi dari artikel di website tersebut bermanfaat bagi pencari informasi dan apakah website tersebut sesuai dengan apa yang ditulis pada judul .

Pertanyaan yang muncul berikutnya adalah mengapa harus bermanfaat dan bagaiman cara mngetahui bahwa suatu website bermanfaat. Jika mengapa harus bermanfaat tentunya kita semua mungkin bisa berasumsi bahwa ketika seseorang memasukkan kata kunci, dia menginginkan informasi yang berkaitan dengan kata kunci yang dia ketikkan. Dia akan berhenti mencari sebuah informasi ketika dia mendapatkan informasi tersebut atau dia selesai mencari referensi yang lain untuk menguatkan informasi tersebut. Jika hal tersebut benar, maka hal itu sesuai dengan tujuan utama mesin pencari google sebagai sarana untuk mendapatkan informasi yang bermanfaat di dunia maya (Kurniadi \& Mulyani, 2017). Sedangkan pertanyaan berikutnya bagaimana google bisa mengetahui website tersebut memberikan informasi yang bermanfaat atau tidak, google sendiri di websitenya sampai penulis menulis tulisan ini belum memberikan informasi yang detail mengenai hal tersebut. 
Jika kita kembali lagi mengingat tentang SEO On-pages pada artikel yang ditulis oleh pihak google, dalam menentukan posisi website di mesin pencari, google lebih mengutamakan pada informasi yang terkandung di dalam website tersebut. Sedangkan Dalam SEO, segala sesuatu yang ada didalam website termasuk metode SEO On-pages. Hal tersebut secara langsung mengartikan bahwa SEO On-pages masih sangat berpengaruh di mesin pencari google.

Pembahasan sub bab ini berkaitan dengan sub bab 4.1 yang masih ada hubunganya dengan informasi yang ada di sebuah website. Karena pada dasarnya objek yang akan di "crawling" adalah konten dari website, entah itu berbentuk tulisan, video, ataupun gambar. Crawling sendiri adalah sebuah kegiatan yang dilakukan oleh robot google untuk mengunjungi website webiste baru maupun website lama yang diupdate dengan tujuan untuk melakukan pengindeksan konten yang ada di website tersebut (Allauddin \& Azam, 2011). Secara otomatis robot google akan menyimpan konten dari website tersebut dalam bentuk link ke dalam database mereka dan akan dihubungkan dengan kata kunci yang cocok untuk konten tersebut. Jadi, jika seseorang memasukkan kata kunci kedalam mesin pencari google, secara otomatis google akan mengeluarkan hasil yang telah dia dapatkan sebelumnya dari crawling tersebut. Pertanyaan yang selanjutnya adalah apa hubungan crawling dengan SEO On-pages? Untuk menjawab pertanyaan tersebut, sebelumya kita harus membuktikan dahulu apakah google di tahun 2021 ini masih menggunakan metode crawling untuk mendapatkan indeks. Untuk itu kita harus membaca aturan dari mesin pencari google yang ditulis di halaman mereka.

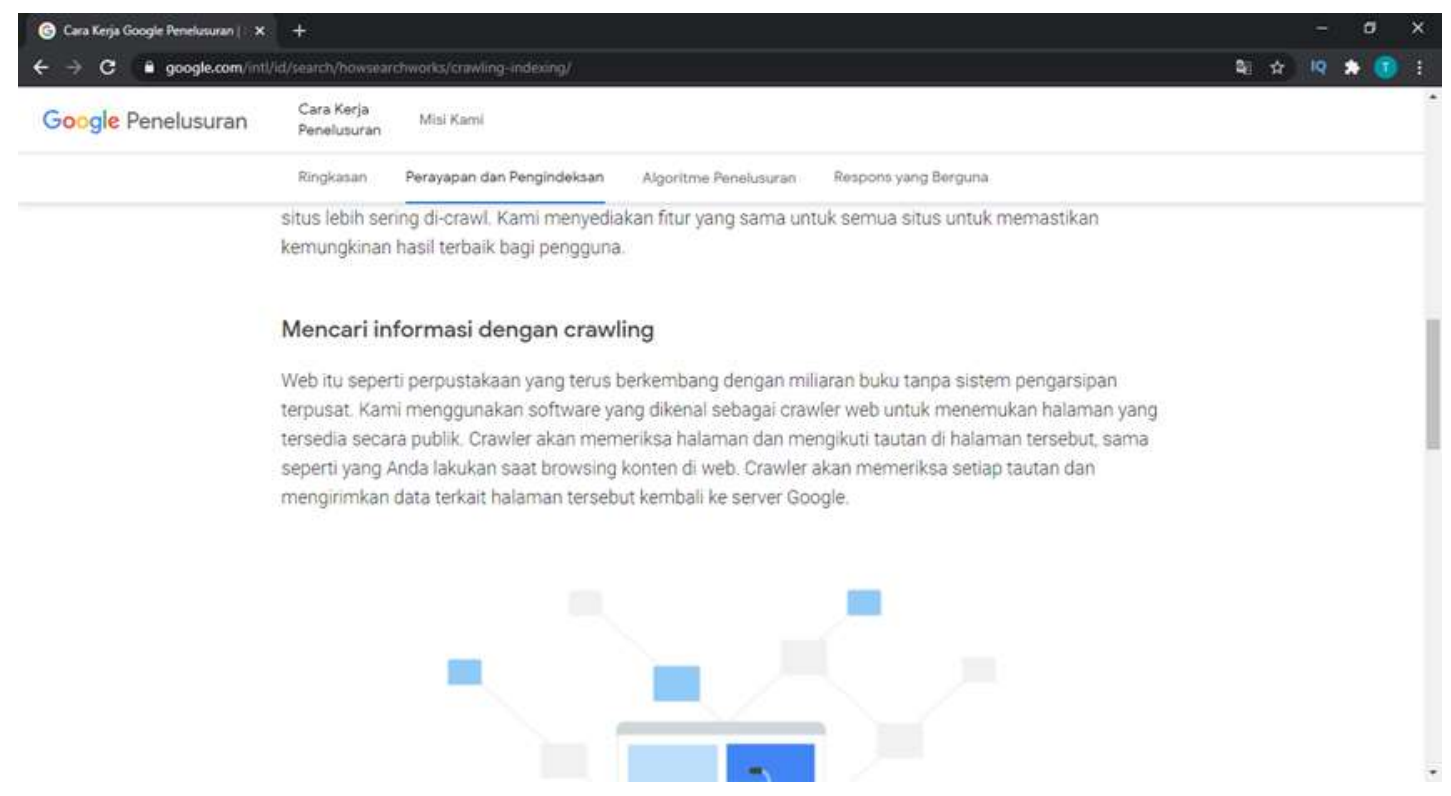

Gambar 2. Penjelasan google crawling

Setelah kita memahami apa itu crawling, kita harusnya sudah bisa menghubungkan dengan index. Index adalah data yang didapat dari hasil crawling yang dilkukan oleh robot google. Dengan begitu kita bisa memahami bahwa crawlng juga bekerja pada on-site meskipun robot google juga menelusuri link yang menuju website lain, misalkan kita membubuhkan alamat referensi tulisan atau sumber gambar yang kita ambil.

Setelah kita mengetahui fakta-fakta mengenai SEO On-pages, lantas apa yang akan kita lakukan pada website kita agar bisa naik di peringkat atas mesin pencarian? Dibagian ini kita akan merangkum beberapa hal penting yang kita dapat dari tulisan google yang telah kita bahas sebelumnya.

1. Meta Title 
Pekerjaan pertama robot google di website kita adalah melakukan pengecekan seluruh link yang ada di webite kita dan menelusurinya. Hal berikutnya adalah mencari kata kunci yang ada di halaman website. Salah satu yang paling sering dijadikan kata kunci adalah Meta title. Setelah robot google melakukan pemindaian terhadap link, hal berikutnya yang dipindai adalah meta title. Itulah kenapa meta title sering dijadikan patokan utama dari isi website tersebut. Algoritma google menjadikan meta title sebagai acuan dari sebuah website apakah isi website tersebut relevan atau tidak dengan membandingkan meta title dengan isi artikel didalam website tersebut. Apakah website tersebut sesuai dari yang digambarkan dengan isinya atau tidak. Untuk membuktikanya, mari coba mengetikkan kata kunci "belajar $S E O$ " di kolom pencarian google.

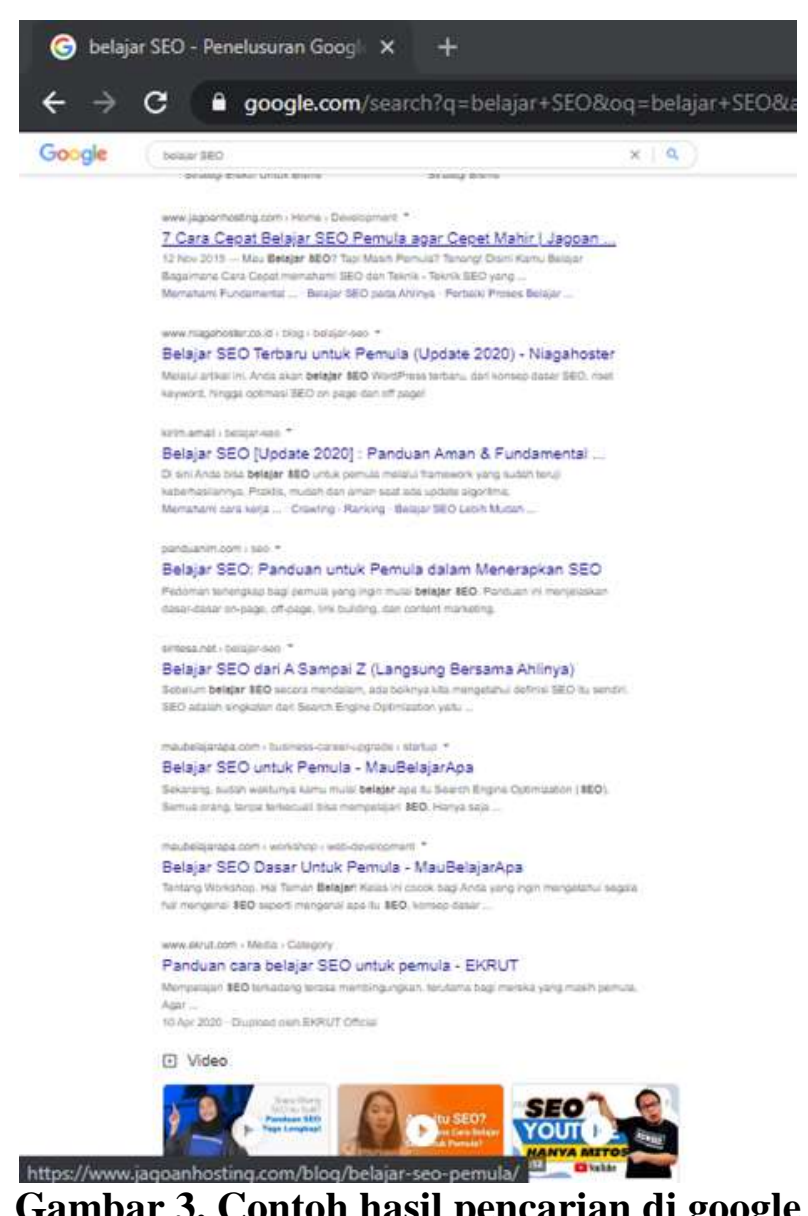

Dari percobaan kecil yang penulis lakukan tersebut, penulis melihat bahwa kata kunci "Belajar SEO" Berada pada meta title di setiap hasil pencarian. Kemudian jika kita melihat potongan artikel setelah meta title, disitu juga terdapat beberapa kata kunci yang muncul entah itu kata kunci yang secara utuh atupun kata kunci yang terpotong di setiap katanya. Namun, kembali lagi bahwa hampir semua hasil pencarian yang muncul memiliki kata kunci yang terdapat pada meta title.

Untuk melihat lebih dalam lagi penulis coba melihat dari segi website yang menyematkan kata kunci di meta title dengan website yang tidak menyematkan kata kunci di meta title. Kata kunci yang kali ini digunakn adalah "sewa mobil jogja". 


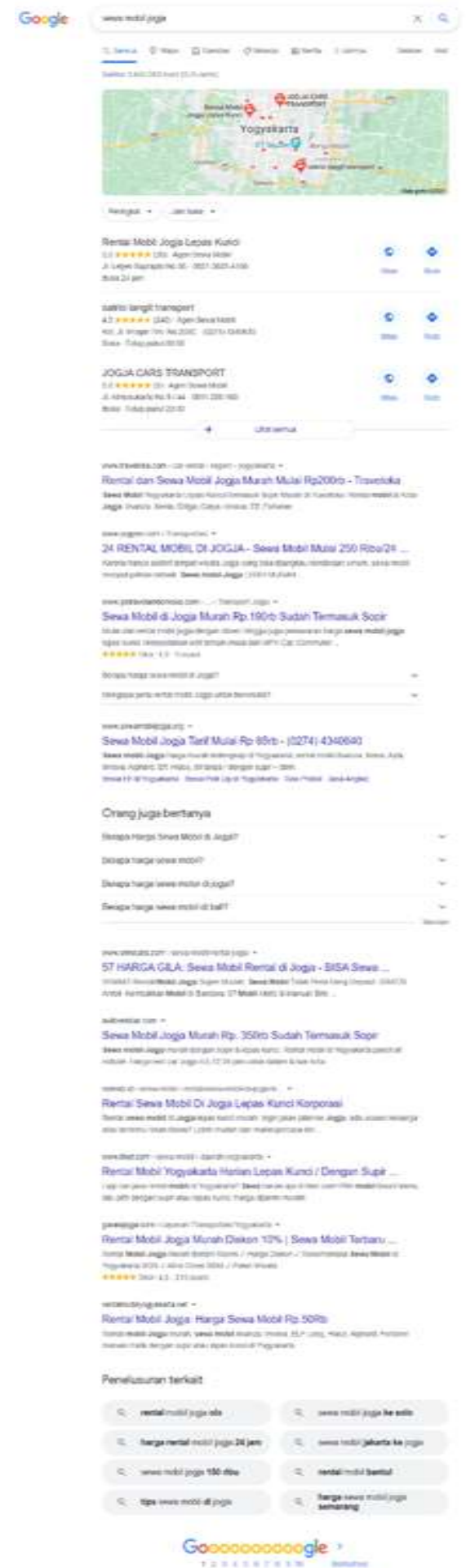

Gambar 4. Contoh hasil pencarian di google halaman pertama

Hasil pencarian di mesin pencari google dengan kata kunci "sewa mobil jogja" pada halaman pertama semua mengandung meta title yang sama dengan kata kunci yang dicari. Tidak terlihat adanya hasil pencarian dengan meta title yang tidak memiliki kata kunci yang dicari. Dari hasil percobaan tersebut dapat diasumsikan bahwa pemberian kata kunci di meta title sedikit banyak mempengaruhi posisi hasil pencarian di mesin pencari google. Namun, belum tentu juga artkel yang tidak menyisipkan kata kunci utama di meta title tidak berpeluang di persaingan mesin pencari google. 


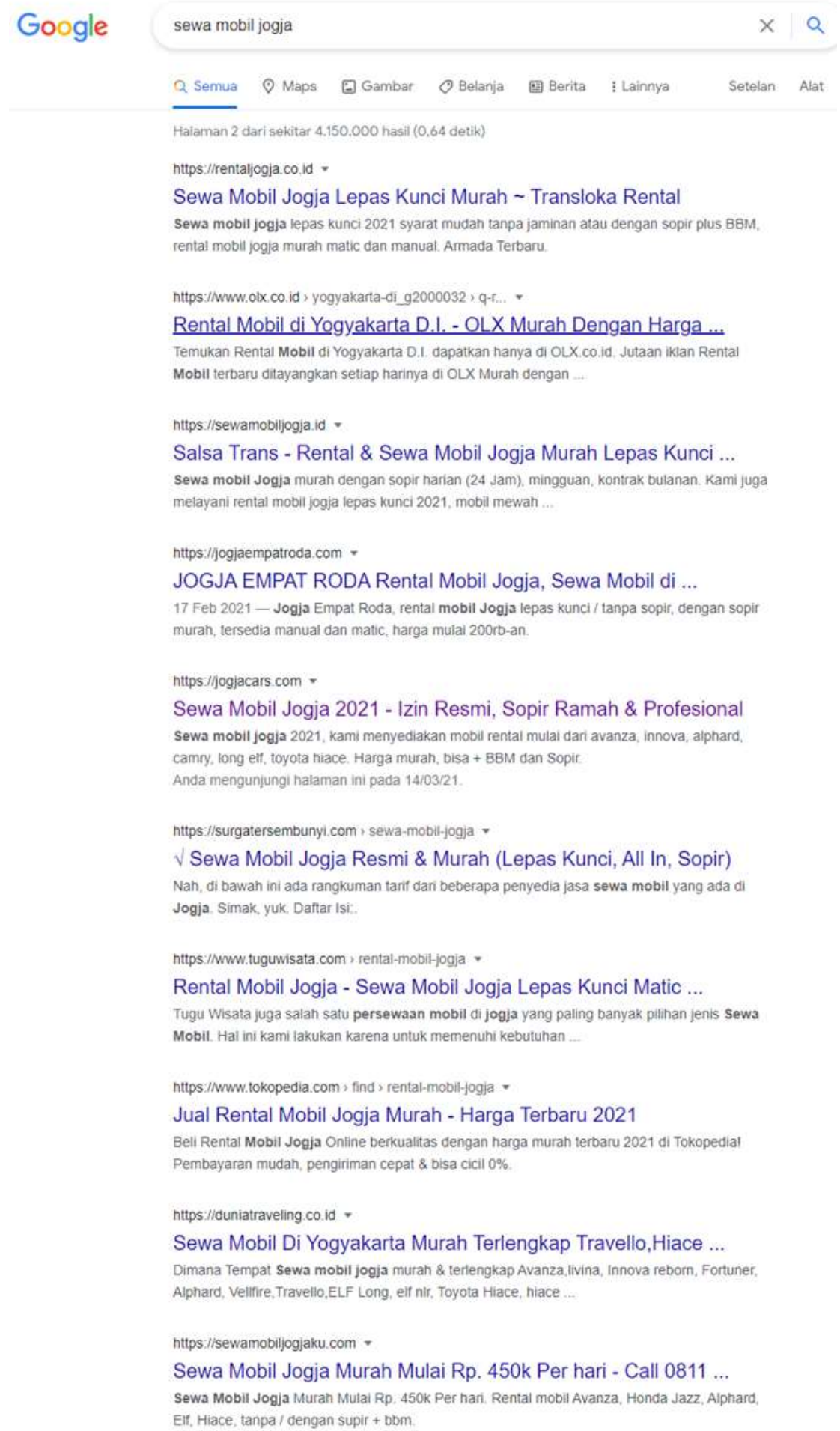

\section{Gambar 5. Contoh hasil pencarian di google halaman kedua}

Pada halaman kedua ini, ada 2 website yang tidak memiliki kata kunci yang dicari pada meta title. Namun, bukan berarti semua website memiliki kesempatan yang sama. Dibutuhkan lebih dari sekedar artikel yang bagus untuk menembus peringkat terebut. Dalam hal ini website yang dapat menembus peringkat atas tanpa memiliki kata kunci yang sama di meta title mereka merupakan website yang memiliki authority yang cukup tinggi, yaitu olx dan tokopedia. 


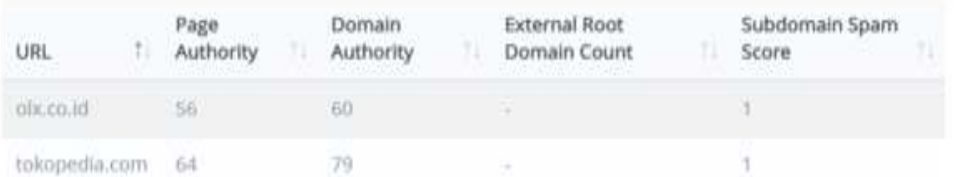

Gambar 6. Authority olx dan tokopedia

2. Meta description

Pada pembahasan sebelumnya penulis menjelaskan mengapa meta title penting untuk disisipi kata kunci. Meta description adalah deskripsi singkat dari artikel yang kita tulis dan muncul pada saat artikel tersebut muncul di mesin pencarian google (No, 2019). Tidak jauh berbeda dari penjelasan sebelumnya, meta description juga harus disisipi kata kunci. Kata kunci yang ada di meta description memperkuat kedudukan artikel tersebut pada tema yang dia pilih. Selain kata kunci utama, kata kunci turunan yang masih berkaitan juga disarankan untuk memperluas jangkauan dari pencarian kata kunci di mesin pencari google. Menyisipkan kata kunci turunan memberikan peluang artikel tersebut keluar di kata kunci yang masih berhubungan dengan kata kunci utama. Contohnya jika kita membuat sebuah artikel tentang "Resep nasi goreng" maka kita bisa menyisipkan kata kunci turunan yang masih terkait misalkan "Vaiasi hidangan nasi goreng" atau bisa juga "Tips memasak nasi goreng ala restoran".

Dengan menambahkan kata kunci turunan, tentunay artikel kita tidak hanya bisa dijangkau lewat google denan kata kunci "Resep Nasi goreng" saja, namun berpeluang untuk dapat dijangkau dengan kata kunci "Variasi hidanan nasi goreng". Dengan meningkatkan peluang artikel yang kita buat untuk lebih banyak muncul di mesin pencarian, harapanya adalah lebih banyak lagi pengunjung website yang kita buat.

\section{SIMPULAN DAN SARAN}

Tahun 2021 ini google masih memperhitungkan SEO on-pages sebagai acuan untuk menyediakan hasil pencarian yang relevan terhadap kata kunci yang dimasukkan oleh pengguna. Banyak hal yang membuktikan hal itu masih dilakukan sampai sekarang. Contohnya adalah crawling sebagai salah satu cara google untuk menyediakan hasil pencarian yang sesuai dengan apa yang diinginkan oleh pengguna. Dengan bukti tersebut, metode peletakan kata kunci yang biasa digunakan untuk optiasi SEO masih sangat diperlukan agar halaman yang dioptimasi dapat naik ke halaman pertama mesin pencarian, atau bahkan menduduki peringkat pertama dari hasil pencarian mesin pencari google dengan kata kunci yang ditarget.

\section{DAFTAR PUSTAKA}

Allauddin, M., \& Azam, F. (2011). Service Crawling using Google Custom Search API. International ..., 34(7), 10-15. Diambil dari

http://scholar.google.com/scholar?hl=en\&btnG=Search\&q=intitle:Service+Crawling+using $+\mathrm{G}$ oogle+Custom+Search+API\#0

Arifin, A., Dengen, N., Setyadi, H. J., Prafanto, A., \& Putra, G. M. (2019). Analisis Penerapan Metode Search Engine Optimization (SEO) Untuk Meningkatkan Traffic Website Berbayar dan Tidak Berbayar. Prosiding Seminar Nasional Ilmu Komputer dan Teknologi Informasi, 4(2). 
Barbar, A., \& Ismail, A. (2019). Search engine optimization (SEO) for websites. ACM International Conference Proceeding Series, Part F1482, 51-55. https://doi.org/10.1145/3323933.3324072

Eka Purwiantono, F. (2019). Metode Search Engine Optimization (SEO) Untuk Meningkatkan Ranking Webometrics Pada Web STIKI Malang. Information System for Educators and Professionals, 3(2), 111-120.

Gupta, S., Agrawal, N., \& Gupta, S. (2016). A Review on Search Engine Optimization: Basics. International Journal of Hybrid Information Technology, 9(5), 381-390. https://doi.org/10.14257/ijhit.2016.9.5.32

Habsy, B. A. (2017). Seni Memehami Penelitian Kuliatatif Dalam Bimbingan Dan Konseling : Studi Literatur. JURKAM: Jurnal Konseling Andi Matappa, 1(2), 90. https://doi.org/10.31100/jurkam.v1i2.56

Harto, A. B. (2019). Implementing Website Design Based on Search Engine Optimization (SEO) Checklist to Increase Web Popularity. Journal of Applied Information, Communication and Technology, 6(2), 87-97. https://doi.org/10.33555/ejaict.v6i2.67

Hasugian, P. S. (2018). Perancangan Website Sebagai Media Promosi Dan Informasi. Journal Of Informatic Pelita Nusantara, 3(1), 82-86.

Kumar, G., \& Paul, R. K. (2020). Literature Review on On-Page \& Off-Page SEO for Ranking Purpose, 01(08), 7-11.

Kurniadi, D., \& Mulyani, A. (2017). Pengaruh Teknologi Mesin Pencari Google Terhadap Perkembangan Budaya dan Etika Mahasiswa. Jurnal Algoritma, 14(1), 19-25. https://doi.org/10.33364/algoritma/v.14-1.19

No, V. (2019). Tinjauan Alur Kerja Copywriter Divisi Konten Suitmedia dalam Industri Kreatif Pemasaran Digital. Jurnal Sosial Humaniora Terapan, 2(1), 35-43. https://doi.org/10.7454/jsht.v2i1.66

Nova, S., Sarjana, P. P., Sistem, J., Bisnis, I., Gunadarma, U., Pustaka, K., ... Perhubungan, K. (n.d.). Analisis Pemanfaatan Media Sosial Dan Website Untuk Penyebaran Informasi Dan Layanan Publik Pada BUMN Di Bawah Kementrian Perhubungan, 1-12.

Prakash, S. S. (2020). Search Engine Optimization Techniques for Attracting Organic Traffic to Websites, 1-6. https://doi.org/10.23883/IJRTER.2020.6025.2V96Z

Setiawan, A., \& Noviyanto, F. (2018). Penerapan Seo (Search Engine Optimization) White Hat Menggunakan Metode Link Kontekstual Untuk Meningkatkan Serp Di Website Infonasa.Com. JSTIE (Jurnal Sarjana Teknik Informatika) (E-Journal), 6(1), 26-37. https://doi.org/10.12928/jstie.v6i1.15175

Wang, F., Li, Y., \& Zhang, Y. (2011). An empirical study on the Search Engine Optimization technique and its outcomes. 2011 2nd International Conference on Artificial Intelligence, Management Science and Electronic Commerce, AIMSEC 2011 - Proceedings, 2767-2770. https://doi.org/10.1109/AIMSEC.2011.6011361

Wu, D., Dong, J., Shi, L., Liu, C., \& Ding, J. (2020). Credibility assessment of good abandonment results in mobile search. Information Processing and Management, 57(6), 102350. https://doi.org/10.1016/j.ipm.2020.102350 